\title{
Persistence, Adherence, and Switch Rates Among Extended-Release and Immediate-Release Overactive Bladder Medications in a Regional Managed Care Plan
}

\author{
Anna O. D'Souza, PhD; Michael J. Smith, PhD, RPh; Lesley-Ann Miller, PhD; \\ Joseph Doyle, RPh, MBA; and Rinat Ariely, MS, MBA
}

\begin{abstract}
BACKGROUND: Pharmacotherapy constitutes an important adjunct to behavioral therapy for the treatment of overactive bladder $(O A B)$. Tolterodine and oxybutynin are commonly prescribed drugs for $O A B$ treatment that exert their beneficial effect by suppressing bladder muscle contractions. However, high discontinuation rates have been observed for these drugs in clinical trials, as well as in real-world settings, in part due to adverse effects. Extended-release (ER) formulations were introduced with an improved tolerability profile over immediate-release (IR) versions of the 2 drugs. No study has compared persistence and adherence to therapy for both the ER and IR versions of tolterodine and oxybutynin.
\end{abstract}

OBJECTIVE: To compare persistence, adherence, and switch rates for the IR and ER formulations of oxybutynin and tolterodine for patients enrolled in a regional managed care plan.

METHODS: Study patients were adults (aged $\geq 18$ years), with at least 1 pharmacy claim for either tolterodine extended-release (tol-ER), oxybutynin extended-release (oxy-ER), tolterodine immediate-release (tol-IR), or oxybutynin immediate-release (oxy-IR) during the period from July 1,1999 , to December 31,2003 , and were continuously eligible for benefits from 6 months before through 12 months after the initial $O A B$ pharmacy claim (index) date. A retrospective cohort study design was used following patients from the index date to the occurrence of non-persistence with the index medication (i.e., a gap of $>45$ days between successive prescription fills or a switch to any other OAB medication), or the end of a 1-year follow-up period, through December 31, 2004. Switching was defined as any change from the index medication, including a change in dose form (e.g., tol-IR to tol-ER), to one of the other 3 study drugs, or to a different $O A B$ treatment (e.g., trospium chloride, oxybutynin patch, flavoxate, hyoscyamine sulfate, or propantheline bromide) during the follow-up period. Adherence was measured as the proportion of patients with a medication possession ratio (MPR) of at least $80 \%$. MPR was calculated as (1) the sum of days supply for all pharmacy claims except the last pharmacy claim, divided by (2) the total number of days from the first fill date to the fill date of the last pharmacy claim. The association of drug therapy with study outcomes was assessed with bivariate and adjusted (multivariate) analyses. Multivariate analyses controlled for demographic and clinical characteristics, plan type, patient out-of-pocket cost for the index medication, and year of therapy initiation.

RESULTS: 1,117 patients had at least 1 pharmacy claim for an OAB study drug ( $n=454$ for tol-ER [40.6\%], $n=249$ for oxy-ER [22.3\%], $n=306$ for tol-IR [27.4\%], $n=108$ for oxy-IR [9.7\%]), of whom $81.6 \%$ were women. The mean (standard deviation [SD]) age of the study population was 55.7 (14.5) years. Only $53.7 \%$ had at least $10 \mathrm{AB}$ diagnosis recorded during the 18-month eligibility period. $44.5 \%$ of patients did not have a refill after the initial (index) pharmacy claim (39.4\% for oxy-ER, $42.7 \%$ for tol-ER, $46.1 \%$ for tol-IR, and $59.3 \%$ for oxy-IR; $P=0.004$ ). Only $13.2 \%$ persisted with treatment for at least 1 year (tol-ER $=15.0 \%$, oxy-ER $=15.3 \%$, tol-IR $=$ $11.4 \%$, oxy-IR=6.5\%; $P=0.050)$. The median days to discontinuation (non-persistency) were 31.0 overall, 33.0 for tol-ER, 34.0 for oxy-ER, 32.0 for tol-IR, and 0 for $0 x y-I R ; P=0.010$. The overall switch rate as a percentage of all study patients was $13.3 \%$, ranging from $9.9 \%$ for tol-ER, $13.7 \%$ for tol-IR, $16.5 \%$ for oxy-ER, and $19.4 \%$ for oxy-IR; $P=0.020$. Of patients who refilled their initial prescription at least once, $24.0 \%$ made a medication switch. Adherence rates as measured by percentage of patients with MPR $\geq 80 \%$ were $30.3 \%$ overall and higher for the ER formulations: $35.2 \%$ for tol-ER, $36.1 \%$ for oxy-ER, $23.5 \%$ for tol-IR, and $14.8 \%$ for oxy-IR; $P<0.001$.

CONCLUSIONS: Adherence was significantly better for ER than IR agents. The high rate of non-persistence (44.5\%) following the first (index) prescription highlights the need for medication counseling by health care professionals.

J Manag Care Pharm. 2008;14(3):291-301

Copyright $\odot$ 2008, Academy of Managed Care Pharmacy. All rights reserved.

\section{What is already known about this subject}

- Tolterodine and oxybutynin are commonly prescribed drugs for treatment of overactive bladder (OAB). In clinical trials and in routine clinical practice, discontinuation rates of these drugs are relatively high (70\% to $90 \%$ in real-world settings), in part due to adverse effects, as well as perceptions of lack of benefit or severity of symptoms requiring therapy.

- Extended-release (ER) formulations of both drugs were developed in part to obtain a better adverse effect profile intended to overcome persistence and adherence issues found with immediate-release (IR) formulations. For instance, a lower proportion of patients using the ER formulations have experienced adverse effects compared with the IR formulations (68\% for oxybutyninER vs. $87 \%$ for oxybutynin-IR, and 30\% for tolterodine-IR vs. 23\% for tolterodine-ER for incidence of dry mouth).

- No studies have been conducted to assess differences in both drug type and formulation in measures of adherence to pharmacotherapy. 


\section{Persistence, Adherence, and Switch Rates Among Extended-Release and Immediate-Release Overactive Bladder Medications in a Regional Managed Care Plan}

\section{What this study adds}

- Only $53.7 \%$ of patients with at least 1 pharmacy claim for tolterodine or oxybutynin had at least 1 medical claim with a diagnosis code for overactive bladder (OAB).

- The rate of persistence with the initially dispensed OAB medication was low; $55.5 \%$ of patients refilled the index prescription, and $13.2 \%$ persisted on their index medication for 1 year.

- $13.3 \%$ of patients overall, and $24.0 \%$ of patients who refilled their initial prescription at least once, switched from their index medication to another $\mathrm{OAB}$ treatment, including between dose forms of the same drug (oxybutynin IR to ER).

- ER formulations of oxybutynin and tolterodine exhibit a statistically significant adherence advantage over IR formulations; patients using IR formulations were $50 \%$ less likely to have an MPR $\geq 80 \%(P<0.001)$

$\mathrm{O}$ veractive bladder $(\mathrm{OAB})$ is a common and chronic condition, characterized by urinary urgency, frequency, or nocturia with or without urge urinary incontinence. ${ }^{1}$ To the extent that such symptoms interfere with social functioning and hygiene, $\mathrm{OAB}$ is considered a medical problem. ${ }^{2}$

Behavioral interventions are considered to be the first-line mode of treatment for $\mathrm{OAB}$ and include lifestyle modifications, scheduling regimens, and pelvic floor muscle rehabilitation. ${ }^{3}$ Pharmacotherapy is an important adjunct with antimuscarinic drugs, such as oxybutynin and tolterodine, considered the agents of first choice., ${ }^{4,5}$ These agents suppress bladder muscle contractions mediated by the muscarinic (primarily $\mathrm{M}_{3}$ ) receptors, thereby increasing bladder capacity and reducing the number and severity of urgency episodes. ${ }^{5-7}$ However, interaction with muscarinic receptors at sites other than that of the bladder muscle or sometimes even at the bladder level itself (e.g., adverse effect of urinary retention) may lead to undesirable adverse effects. $^{7-9}$ Approaches to overcoming such concerns include the development of extended-release (ER) formulations and agents with greater M3 selectivity, such as trospium, solifenacin, and darifenacin, which were introduced in 2004.

For pharmacotherapy to be beneficial, good persistence and adherence are essential. High discontinuation rates have been observed in clinical trials of $\mathrm{OAB}$ drugs, due in part to adverse effects including but not limited to dry mouth, constipation, blurred vision, and headache. Drug persistence and adherence patterns assessed for various $O A B$ drugs in real-world settings are even worse with almost $70 \%$ to $90 \%$ of patients discontinuing treatment within 1 year. ${ }^{10-18}$ The persistence drops markedly within the first 6 months and is further reduced at 1 year. In studies that have a 6-month follow-up, persistence rates of $11 \%$ to $30 \%$ have been reported,,$^{10,11,16,18}$ and in studies with at least 1 year of follow-up, persistence rates range from $8 \%$ to $29 \%$. $^{12,13,16-18}$
In general, oxybutynin immediate-release (oxy-IR) has the lowest persistency rate, and tolterodine extended-release (tol-ER) has the highest persistency rate. However, no studies have compared both the extended-release (ER) and immediate-release (IR) versions of oxybutynin and tolterodine simultaneously to assess differences in outcomes by both drug type and formulation. Furthermore, available published studies often exclude important covariates due to lack of data. ${ }^{12,17}$ For example, insurance coverage for prescription drugs is an excluded covariate that is likely to affect persistency patterns in $\mathrm{OAB}$ because pharmacotherapy in OAB usually competes with first-line, behavioral therapy techniques. In fact, 1 study found that prescription drug coverage was the most important factor determining patient preference for drug therapy. ${ }^{19}$

The present study addresses these issues by simultaneously comparing both ER and IR forms of tolterodine (tol-ER, tol-IR) and oxybutynin (oxy-ER, oxy-IR, respectively) using various measures of adherence to treatment and accounting for additional relevant factors not previously addressed. The present study was limited to these $4 \mathrm{OAB}$ compounds, because the number of patients using these drugs during the study period was sufficient to allow for statistically meaningful analysis. While measurement of persistence provides information on adherence in terms of the timeliness and consistency of refilling, ${ }^{20}$ assessment of the medication possession ratio (MPR) provides insight into the availability of medication. ${ }^{21,22}$ This measure is important as $\mathrm{OAB}$ patients may exhibit sporadic refilling patterns depending on their perceived need. Therefore, in this study we compared the 4 drug products, both on measures of persistence in terms of discontinuation or switching to other OAB drugs, and also adherence rates using the MPR, while adjusting for important covariates, including patient demographics, type of insurance coverage, prescriber specialty, and comorbidities.

\section{Methodology}

\section{Data Source}

The study population comprised enrollees of a regional managed care health plan covering 225,000 enrollees of whom approximately $70 \%$ have prescription drug coverage. Medicaid recipients were not included in the total population of this health plan, and, consequently, data were available only for privately insured, Medicare, and self-insured employers. Information was obtained on paid pharmacy and medical claims made between January 1, 1999, and December 31, 2004 (total study period). All claims data were linked to eligibility data containing demographic and eligibility information by an encrypted identification number to protect patient and provider confidentiality. The study protocol was deemed exempt by West Virginia University's Institutional Review Board for the Protection of Human Subjects.

The pharmacy claims database included details, such as National Drug Code, date dispensed, quantity dispensed, days supply, copayment/coinsurance amount, and prescribing 


\section{Persistence, Adherence, and Switch Rates Among Extended-Release and Immediate-Release Overactive Bladder Medications in a Regional Managed Care Plan}

provider specialty. Prescriber specialty was obtained by matching a provider identifier on the pharmacy claim to a crosswalk table indicating each provider's specialty. The medical claims database included details of the visits or services provided, such as International Classification of Diseases, Ninth Revision, Clinical Modification (ICD-9-CM) diagnosis and procedure codes, date of service, location of service, Current Procedural Terminology procedure codes, billing codes, and provider specialty. Additional information on subjects (e.g., age, gender, plan type) and dates of enrollment were available in a separate eligibility file.

\section{Study Design and Sample Selection}

Health plan enrollees with pharmacy coverage were first selected (n approximately 154,000), and then those with a pharmacy claim for tol-ER, oxy-ER, tol-IR, or oxy-IR between July 1, 1999, and December 31, 2003, were identified (Figure). Of the 4 study drugs, 3 (oxy-ER, oxy-IR, and tol-IR) were available in the United States throughout the entire study period, while tol-ER was launched in September 2001. The date of the earliest OAB pharmacy claim for a person during this period was defined as the index date (start date), and the associated pharmacy claim was defined as the index prescription. The 6-month period before the index date was defined as the baseline period, and the 12-month period after the index date was the follow-up period, yielding a total of 18 months during which subjects were required to be continuously eligible for both medical and pharmacy benefits. Subjects were excluded if they were aged $<18$ years or if they had pharmacy claims for any study drug during the baseline period (6 months before the [index] start date) to increase the likelihood that the initiation of $\mathrm{OAB}$ pharmacotherapy was assessed. The pattern of fills following the index prescription was evaluated for 12 months after the index date using a retrospective cohort study design to determine non-persistence, switching, and MPR.

\section{Study Outcomes}

Persistence was measured as the proportion of patients continuing therapy for 12 months without discontinuing the index drug or switching to other OAB drugs. Patients were considered to be non-persistent on their index medication if they failed to refill their index prescription within a defined 'grace' period of 45 days from the expected end of supply of the previous prescription, or if a person filled a prescription for an $O A B$ drug different from the index prescription (i.e., switched, but filled it within the 'grace' period). Thus, non-persistence was defined as not refilling the index prescription in a timely manner or switching from the index medication. The 'grace' period used in previous studies has ranged from 15 to 45 days. ${ }^{11,17}$ Our study used a 45 -day period to include patients with intermittent use, which is thought to be prevalent in $\mathrm{OAB}$. The number of days to non-persistence was calculated as the difference between the fill date of the last prescription and the fill date of the index prescription. The count of days to non-persistence did not include the days supply in

\section{FIGURE Study Sample Extraction}

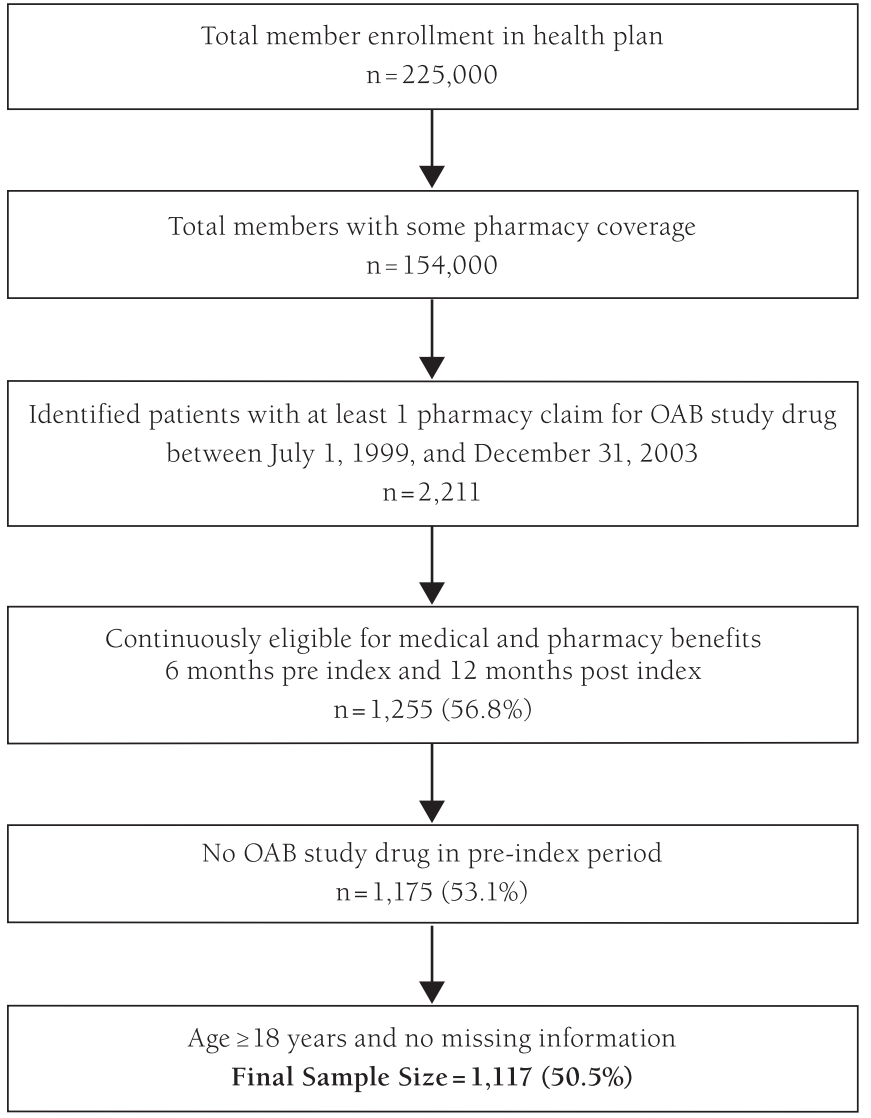

the last pharmacy claim because a discontinuation or switch could have occurred at any time during the period covered by the final claim. Consequently, excluding the entire days supply of the last filled prescription yields the lowest estimate of days of persistence.

The switch rate was calculated as the proportion of patients who refilled at any time during the 12-month follow-up but changed from the initial (index) medication to any of the other 3 study drugs, including within-drug changes to a different dose form (oxy-IR to oxy-ER), or to a different OAB treatment (e.g., trospium chloride, oxybutynin transdermal, flavoxate, hyoscyamine sulfate, or propantheline bromide).

Adherence rate was measured as the proportion of patients with an MPR of at least $80 \%$. The MPR for each person was calculated as (1) the sum of the total number of days of a medication supplied across pharmacy claims except for the last pharmacy claim, divided by (2) the total number of days from the first fill date to the fill date of the last pharmacy claim. For example, a patient who receives 90-days supply during a 120-day period will have 


\section{Persistence, Adherence, and Switch Rates Among Extended-Release and Immediate-Release Overactive Bladder Medications in a Regional Managed Care Plan}

\begin{tabular}{l|l}
\hline TABLE 1) & ICD-9-CM Codes for Overactive Bladder \\
\hline ICD-9-CM code & \multicolumn{1}{c}{ ICD-9-CM Description } \\
\hline 788.30 & Urinary incontinence, unspecified \\
\hline 788.31 & Urge incontinence \\
\hline 788.33 & Mixed incontinence \\
\hline 788.34 & Incontinence without sensory awareness \\
\hline 788.35 & Postvoid dribbling \\
\hline 788.36 & Nocturnal enuresis \\
\hline 788.37 & Continuous leakage \\
\hline 788.39 & Other urinary incontinence \\
\hline 788.40 & Frequency of urination, unspecified \\
\hline 788.41 & Urinary frequency \\
\hline 788.42 & Polyuria \\
\hline 788.43 & Nocturia \\
\hline 596.51 & Hypertonicity of bladder \\
\hline
\end{tabular}

ICD-9-CM=International Classification of Diseases, Ninth Revision, Clinical Modification

$\mathrm{MPR}=0.75$. The MPR can be calculated only for patients who have at least 2 pharmacy fills. Thus, MPR is 0 for patients who did not refill their index prescription. Additionally, MPR values were capped at 1.0 for patients who refilled early.

\section{Study Covariates and Statistical Analyses}

Demographic covariates included age and gender. Covariates accounting for differences in structure and nature of coverage included the plan type (e.g., privately insured, Medicare, and self-insured employers) and average out-of-pocket (OOP) cost for the index $\mathrm{OAB}$ drug. The latter was computed as the mean of copayment/coinsurance costs for all pharmacy claims of the index drug. Clinical covariates included presence of an $\mathrm{OAB}$ diagnosis (Table $1^{1,23,24}$ ) in any diagnosis field on the claim, specialty (e.g., urologist, gynecologist, or other) of the provider who prescribed the index prescription, a modified D'Hoore Charlson Comorbidity Index (CCI) score in the 6-month baseline period, presence of OAB-related comorbidities (e.g., urinary tract infection/ vulvovaginitis, anxiety/depression, falls/fractures/skin infections/ pressure ulcers ${ }^{25,26}$ in the 6-month baseline period, and average daily dose for the index medication. Average daily dose for the index medication was calculated per patient over the period of that patient's observation utilizing all fills of the index medication until discontinuation or switch occurred and expressed as mg per day. The effect of dose was assessed using the categories "low" and "normal to high" dose defined as follows:

\section{Low Dose Normal-to-High Dose}

$\begin{array}{lll}\text { tol-ER } & =2 \mathrm{mg} \text { per day } & >2 \mathrm{mg} \text { per day } \\ \text { tol-IR } & \leq 2 \mathrm{mg} \text { per day } & >2 \mathrm{mg} \text { per day } \\ \text { oxy-ER } & =5 \mathrm{mg} \text { per day } & >5 \mathrm{mg} \text { per day } \\ \text { oxy-IR } & \leq 10 \mathrm{mg} \text { per day } & >10 \mathrm{mg} \text { per day }\end{array}$

These categories broadly reflect the doses recommended in U.S. prescribing information (tol-ER/IR: $2 \mathrm{mg}-4 \mathrm{mg}$ per day; oxy-ER: 5 mg-30 mg per day; oxy-IR: 5 mg-20 mg per day). ${ }^{27-30}$

Univariate analyses, such as Analysis of Variance (ANOVA), and Kruskal-Wallis test for continuous variables, and log-rank and chi-squares tests for categorical variables were used to compare study outcomes and characteristics (demographic, plan, and clinical). Appropriateness of non-parametric testing was tested after checking normality diagnostics (Kolmogorov-Smirnov tests, Q-Q plots, histograms). For the log-rank test, the Breslow test statistic was used to find differences in time to event, which provides greater weight to early observations, thereby increasing the likelihood of finding a difference, if one exists, in contrast to other test statistics that equally weight all cases. Logistic regression models were used to determine differences in switch and adherence rates between drug therapy groups. Cox-Proportional Hazards (Cox-PH) regression was used to determine differences in time to non-persistence between drug therapy groups. All multivariate analyses controlled for demographic, plan, clinical characteristics, and year of index drug. ${ }^{31,32}$ The latter was included in an attempt to account for possible changes in treatment trends over time associated with the introduction of tol-ER in September 2001. All multivariate analyses were preceded by testing for outliers and the assumptions of the particular regression used. The assumption of proportional hazards was tested for the Cox-PH regression using the global test of proportional hazards, including all covariates together with the interaction terms of each covariate with the logarithm of time. For the logistic regression, the possibilities of multicollinearity and near-dependency were assessed by checking for very large parameter estimates and standard errors. Three cases were found to be outliers, but study results were similar with and without the outliers. Hence, final analyses are reported for the entire sample. When necessary, continuous variables were categorized to avoid problems with outliers, and categorical variables were collapsed to produce cells of adequate size.

Tests of significance comparing each drug group to the reference drug group (tol-ER) were obtained from the regression conducted for each outcome (e.g., persistence, switch rate, and adherence). When a significant difference across the 4 drug groups was found by either drug type or formulation, a subsequent test for significance was conducted for the specific outcome measure by pooling the oxybutynin or tolterodine drug groups or the ER and IR groups. All regressions used the sequential block-entry approach, which assesses the impact of type of drug therapy after all covariates have already entered the model. Adjusted persistence rates were obtained from the Cox-PH model. Adjusted switch and adherence rates were obtained by substituting mean values for all covariates in the logistic regression equations to produce predicted values for each group. Data were manipulated using SAS version 9.1.3 (SAS Institute, Inc., Cary, NC) and analyzed using SPSS version 13.0 (SPSS Inc., Chicago, IL) and SAS version 9.1.3. 


\section{Persistence, Adherence, and Switch Rates Among Extended-Release and Immediate-Release Overactive Bladder Medications in a Regional Managed Care Plan}

\section{TABLE 2 Characteristics of Study Sample at Baseline by OAB Therapy}

\begin{tabular}{|c|c|c|c|c|c|c|}
\hline \multirow[b]{2}{*}{ Characteristics } & \multicolumn{6}{|c|}{ Index OAB Therapy } \\
\hline & TOTAL & $\begin{array}{c}\text { tol-ER } \\
(\mathrm{N}=454)\end{array}$ & $\begin{array}{c}\text { oxy-ER } \\
(\mathrm{N}=249)\end{array}$ & $\begin{array}{c}\text { tol-IR } \\
(\mathrm{N}=306)\end{array}$ & $\begin{array}{l}\text { oxy-IR } \\
(\mathrm{N}=108)\end{array}$ & $P$ Value $^{\mathrm{a}}$ \\
\hline Age in years, mean [SD] & $55.7[14.5]$ & 56.9 [13.9] & $56.3[6.4]$ & $55.1[14.4]$ & 55.8 [14.9] & $0.070^{\mathrm{b}}$ \\
\hline Gender, female & $81.6 \%$ & $83.7 \%$ & $79.5 \%$ & $82.0 \%$ & $75.9 \%$ & $0.220^{c}$ \\
\hline \multicolumn{7}{|l|}{ Plan type } \\
\hline Privately insured & $58.3 \%$ & $57.3 \%$ & $56.6 \%$ & $63.1 \%$ & $52.8 \%$ & $0.002^{\mathrm{c}}$ \\
\hline Medicare & $19.1 \%$ & $22.9 \%$ & $21.7 \%$ & $11.4 \%$ & $18.5 \%$ & \\
\hline ASO & $22.6 \%$ & $19.8 \%$ & $21.7 \%$ & $25.5 \%$ & $28.7 \%$ & \\
\hline \multicolumn{7}{|c|}{ Average out-of-pocket costs per person for index OAB Rx } \\
\hline Median \$ & $\$ 15.00$ & $\$ 16.74$ & $\$ 15.00$ & $\$ 11.94$ & $\$ 5.85$ & $<0.001^{\mathrm{d}}$ \\
\hline Mean \$ & $\$ 16.57$ & $\$ 19.50$ & $\$ 17.02$ & $\$ 14.77$ & $\$ 8.38$ & \\
\hline Prescribing urologist or gynecologist & $28.2 \%$ & $28.0 \%$ & $24.1 \%$ & $33.3 \%$ & $24.1 \%$ & $0.073^{c}$ \\
\hline OAB diagnosis $^{e}$ & $53.7 \%$ & $55.9 \%$ & $61.0 \%$ & $49.0 \%$ & $40.7 \%$ & $0.001^{c}$ \\
\hline \multicolumn{7}{|l|}{ Average daily dose ${ }^{\mathrm{f}}$} \\
\hline Low & $25.5 \%$ & $8.4 \%$ & $51.8 \%$ & $18.0 \%$ & $58.3 \%$ & $<0.001^{\mathrm{c}}$ \\
\hline Normal to high & $74.5 \%$ & $91.6 \%$ & $48.2 \%$ & $82.0 \%$ & $41.7 \%$ & \\
\hline \multicolumn{7}{|l|}{ Baseline $^{\mathrm{g}}$ D'Hoore CCI } \\
\hline Median & 0.0 & 0.0 & 0.0 & 0.0 & 0.0 & $0.040^{\mathrm{d}}$ \\
\hline Mean & 0.79 & 0.79 & 0.92 & 0.64 & 0.96 & \\
\hline $\begin{array}{l}\text { Baseline }{ }^{g} \text { prevalence of urinary tract } \\
\text { infection/vulvovaginitis }\end{array}$ & $20.0 \%$ & $20.0 \%$ & $22.5 \%$ & $17.6 \%$ & $20.4 \%$ & $0.150^{c}$ \\
\hline $\begin{array}{l}\text { Baselineg prevalence of skin infection/ } \\
\text { pressure ulcer }\end{array}$ & $0.1 \%$ & $0.9 \%$ & $0.8 \%$ & $1.0 \%$ & $0.0 \%$ & $0.960^{d}$ \\
\hline Baseline ${ }^{g}$ prevalence of anxiety/depression & $16.8 \%$ & $19.8 \%$ & $15.3 \%$ & $15.7 \%$ & $11.1 \%$ & $0.100^{c}$ \\
\hline Baseline ${ }^{g}$ prevalence of falls/fractures & $5.3 \%$ & $4.6 \%$ & $2.4 \%$ & $8.2 \%$ & $6.5 \%$ & $0.020^{c}$ \\
\hline
\end{tabular}

a $P$ values are for comparisons among all $O A B$ therapies and do not represent differences between any $2 O A B$ therapies. Thus, a significant $P$ value represents a difference among $O A B$ therapy groups in the particular characteristic $\alpha=0.05$. Significant values are in bold.

b ANOVA test.

c Pearson $X 2$ test.

d Kruskal-Wallis $x^{2}$ test.

e Assessed during entire 18-month eligibility period.

f Dosing classification:

$\begin{array}{llc} & \text { Low Dose } & \text { Normal-to-High Dose } \\ \text { tol-ER } & =2 \mathrm{mg} \text { per day } & >2 \mathrm{mg} \text { per day } \\ \text { tol-IR } & \leq 2 \mathrm{mg} \text { per day } & >2 \mathrm{mg} \text { per day } \\ \text { oxy-ER } & =5 \mathrm{mg} \text { per day } & >5 \mathrm{mg} \text { per day } \\ \text { oxy-IR } & \leq 10 \mathrm{mg} \text { per day } & >10 \mathrm{mg} \text { per day }\end{array}$

$\mathrm{g}$ Assessed during 6-month pre-index period.

$A S O=$ administrative services only; $C C I=C h a r l s o n$ Comorbidity Index; $O A B=$ overactive bladder; oxy-ER=oxybutynin extended-release; oxy-IR=oxybutynin immediaterelease; $R x=$ prescription; tol-ER= tolterodine extended-release; tol-IR=tolterodine immediate-release.

\section{Results}

\section{Study Sample Description}

To derive the study sample, enrollees with any pharmacy coverage were first selected $(70 \%$ of $225,000=$ approximately 154,000$)$. Of these enrollees, 2,211 patients with at least 1 pharmacy claim for an OAB study drug between July 1, 1999, and December 31, 2003, were identified (Figure). A total of 1,255 patients remained after excluding patients without continuous eligibility for both medical and pharmacy benefits from the 6-month period before through the 12-month period after the index prescription. Further, excluding patients having any $\mathrm{OAB}$ study drug in the pre-index period, those aged $<18$ years of age, and those with missing data, a final sample size of 1,117 was obtained (Figure).

For this study sample $(\mathrm{n}=1,117)$, the most commonly prescribed index drug was tol-ER $(\mathrm{n}=454,40.6 \%)$, followed by tol-IR $(n=306,27.4 \%)$, oxy-ER $(n=249,22.3 \%)$, and oxy-IR $(n=108$, 9.7\%). The average (standard deviation [SD]) age of the study sample was 55.7 (14.5) years with a predominance of women 


\section{Persistence, Adherence, and Switch Rates Among Extended-Release and Immediate-Release Overactive Bladder Medications in a Regional Managed Care Plan}

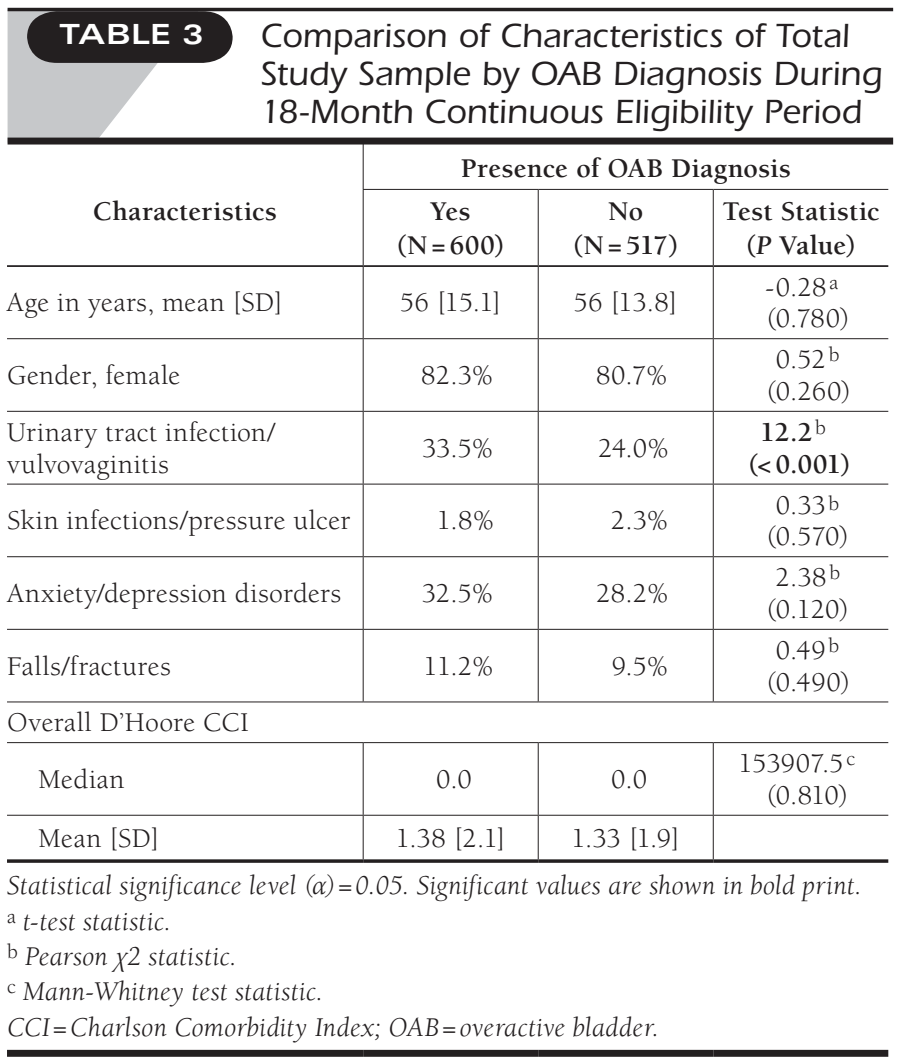

(81.6\%) and comparable demographics across treatment groups (Table 2). Many patients had OAB-related comorbidities; during the 6-month baseline period, 20.0\% of patients were diagnosed with urinary tract infection (UTI)/vulvovaginitis, and 16.8\% with anxiety/depression. These findings were consistent with published estimates ${ }^{25}$ and did not differ among treatment groups. However, patients prescribed oxybutynin (ER or IR) had more comorbidities (measured as higher mean baseline D'Hoore CCI scores, $P=0.040$ ), and patients prescribed IR formulations had higher baseline rates of falls and fractures $(P=0.020)$.

The study population was selected on $\mathrm{OAB}$ prescription drug use and not on the presence of a diagnosis. A little more than half (53.7\%) of patients had an OAB diagnosis. The percentage with an $\mathrm{OAB}$ diagnosis was higher for ER-treated patients (55.9\% for tol-ER, $61.0 \%$ for oxy-ER) than for IR-treated patients (49.0\% for tol-IR, $40.7 \%$ for oxy-IR, $P=0.001$ ). However, baseline characteristics were similar in patients with and without an $O A B$ diagnosis, except for a higher prevalence of comorbid UTI/ vulvovaginitis in the patients diagnosed with $\mathrm{OAB}$ (Table 3, $P<0.001$ ). Only $28.2 \%$ of patients received their index prescription from an urologist or gynecologist with no significant difference in specialty use by type of agent (Table 2).

Average per-patient OOP costs for the index drug differed significantly by type of index drug received, being lowest for
oxy-IR (\$8.38) (reflecting its generic status), and highest for tol-ER (\$19.50), and oxy-ER (\$17.02). The type of plan was also significantly related to type of index drug. IR-treated patients were more often members of self-insured employers than ER-treated patients, and patients prescribed tol-IR were more likely to be privately insured and less likely to be Medicare beneficiaries than were patients prescribed other therapies. There were also distinct differences between groups in their average daily doses of the index drug. More patients were in the normalto-high dose category for tolterodine (91.6\% for tol-ER and $82.0 \%$ for tol-IR) than oxybutynin (48.2\% for oxy-ER and $41.7 \%$ for oxy-IR; $P<0.001$ ).

\section{Study Outcomes}

Persistence: The percentage of patients whose treatment persisted for 12 months with the index drug without any gaps exceeding 45 days was $13.2 \%$ (tol-ER $=15.0 \%$, oxy-ER $=15.3 \%$, tol- $\mathrm{IR}=11.4 \%$, oxy-IR $=6.5 \% ; P=0.050)$. The bivariate analysis tested for differences among all 4 therapies $(P=0.050)$, with no differences seen between the ER forms (Table 4). Almost half of all patients (44.5\%) did not refill their index prescription; the highest proportion of non-refills was seen for oxy-IR (59.3\%), followed by tol-IR (46.1\%), tol-ER (42.7\%), and then oxy-ER (39.4\%) (Table 4). Because the time to non-persistence was calculated as the difference in days between the fill dates of the last pharmacy claim and the index prescription, subjects who did not refill their index prescription had 0 days to non-persistence. Oxy-IR users had the shortest median time to non-persistence ( 0 days), and mean time to discontinuation or switch (61 days, compared with 84 to 98 days for other drug products; Table 4). However, when the drug variables were added to a Cox-PH model containing the other covariates, the drug effect was not statistically significant $(P=0.363)$. Adjusted persistence rates at the end of follow-up were $11.0 \%$ for tol-ER, $13.2 \%$ for oxy-ER, $9.0 \%$ for tol-IR, and $9.0 \%$ for oxy-IR (Table 5). No other covariates were found to affect time to non-persistence, including demographics, plan type, or level of copayment.

Switch Rate: Only $13.3 \%$ of the cohort overall and $24.0 \%$ of patients who refilled their index prescription switched from the index medication to other $\mathrm{OAB}$ drugs. In the bivariate analysis, switch rates were lowest for patients initiated on tol-ER $(9.9 \%$, Table 4). Logistic regression analysis (not shown) indicated that this result was significantly influenced by the year of index $O A B$ therapy; patients were more likely to switch if prescribed their index drug in 2000 or 2001 than in 2003 (2000: odds ratio $[\mathrm{OR}]=2.336, P=0.027 ; 2001: \mathrm{OR}=4.551, P<0.001)$. However, after accounting for other variables, oxy-ER or oxy-IR users remained twice as likely to switch compared with tol-ER users, while tol-IR users did not differ significantly from tol-ER users. After pooling data by drug type, the odds of switching remained significantly different between oxybutynin and tolterodine $(\mathrm{OR}=1.751$; 95\% CI, 1.147-2.673; $P=0.009$, data not shown). 


\section{Persistence, Adherence, and Switch Rates Among Extended-Release and Immediate-Release Overactive Bladder Medications in a Regional Managed Care Plan}

\section{TABLE 4 Unadjusted Study Outcomes of Study Sample by OAB Therapy}

\begin{tabular}{|c|c|c|c|c|c|c|}
\hline \multicolumn{7}{|c|}{ Characteristics of Index OAB Therapy } \\
\hline & Total & $\begin{array}{c}\text { tol-ER } \\
(\mathrm{N}=454)\end{array}$ & $\begin{array}{c}\text { oxy-ER } \\
(\mathrm{N}=249) \\
\end{array}$ & $\begin{array}{c}\text { tol-IR } \\
(\mathrm{N}=306)\end{array}$ & $\begin{array}{c}\text { oxy-IR } \\
(\mathrm{N}=108) \\
\end{array}$ & $\begin{array}{c}\text { Test Statistic } \\
(P \text { Value })\end{array}$ \\
\hline Persistence on index Rx & $\begin{array}{l}13.2 \% \\
(148)\end{array}$ & $\begin{array}{l}15.0 \% \\
(68)\end{array}$ & $\begin{array}{l}15.3 \% \\
(38)\end{array}$ & $\begin{array}{l}11.4 \% \\
(35)\end{array}$ & $\begin{array}{l}6.5 \% \\
(7)\end{array}$ & $\begin{array}{r}7.23^{b} \\
(0.050)\end{array}$ \\
\hline \multicolumn{7}{|l|}{ Days to non-persistency } \\
\hline Median & 31.0 & 33.0 & 34.0 & 32.0 & 0.0 & $\begin{array}{l}11.82^{\mathrm{c}} \\
(0.010)\end{array}$ \\
\hline Mean & 90.5 & 97.5 & 97.8 & 84.2 & 61.0 & \\
\hline \multicolumn{7}{|l|}{ Refilled index Rx } \\
\hline Yes & $55.5 \%$ & $57.3 \%$ & $60.6 \%$ & $53.9 \%$ & $40.7 \%$ & $13.08^{b}$ \\
\hline No & $44.5 \%$ & $42.7 \%$ & $39.4 \%$ & $46.1 \%$ & $59.3 \%$ & $(0.004)$ \\
\hline Switch rate & $\begin{array}{l}13.3 \% \\
(149)\end{array}$ & $\begin{array}{l}9.9 \% \\
(45) \\
\end{array}$ & $\begin{array}{l}16.5 \% \\
(41)\end{array}$ & $\begin{array}{l}13.7 \% \\
(42)\end{array}$ & $\begin{array}{l}19.4 \% \\
(21)\end{array}$ & $\begin{array}{c}10.24^{b} \\
(0.020)\end{array}$ \\
\hline $\begin{array}{l}\text { Adherence } \\
M P R \geq 0.8\end{array}$ & $\begin{array}{l}30.3 \% \\
(338)\end{array}$ & $\begin{array}{l}35.2 \% \\
(160)\end{array}$ & $\begin{array}{l}36.1 \% \\
(90)\end{array}$ & $\begin{array}{l}23.5 \% \\
(72)\end{array}$ & $\begin{array}{l}14.8 \% \\
(16)\end{array}$ & $\begin{array}{l}28.20^{\mathrm{b}} \\
(<0.001)\end{array}$ \\
\hline
\end{tabular}

All values are \% (n) unless otherwise specified.

a $P$ values are for comparisons among all $O A B$ therapies and do not represent differences between any $2 O A B$ therapies. Thus, a significant $P$ value represents a difference among $O A B$ therapy groups in the particular characteristic. Statistical significance level $(\alpha)=0.05$. Significant values are shown in bold print.

b Pearson $x^{2}$ statistic.

c Breslow test statistic

$C C I=$ Charlson Comorbidity Index; $O A B=$ overactive bladder; oxy-ER=oxybutynin extended-release; oxy-IR=oxybutynin immediate-release; $R x=$ prescription; tol-ER=tolterodine extended-release; tol-IR=tolterodine immediate-release.

The presence of an $\mathrm{OAB}$ diagnosis increased the odds of switching $(\mathrm{OR}=1.643)$. Additionally, patients prescribed their index drug by an urologist or gynecologist were $43 \%$ less likely to switch than those prescribed their index drug by a physician with other specializations (data not shown). Adjusted switch rates for the 4 therapies are shown in Table 5.

Adherence rate: The 4 drug groups differed significantly in the proportion of patients who possessed medication for at least $80 \%$ of the duration of their therapy. Of note, more than $33 \%$ of patients in the ER drug groups possessed medication for $80 \%$ of their therapy duration compared with less than $25 \%$ of patients receiving tol-IR and fewer than 1 in 6 on oxy-IR (Table 4). The lower proportion of adherent patients in the oxy-IR group reflects the lower persistence in this group. (Highly persistent patients have higher MPR values in our analysis because we assigned an MPR of 0 to patients who failed to refill their index prescription.)

The logistic regression model (not shown) mirrored the univariate results; odds of MPR $\geq 80 \%$ were significantly lower for tol-IR and oxy-IR than tol-ER (tol IR OR=0.615, P=0.021; oxy-IR $\mathrm{OR}=0.355, P=0.002$ ). There was no significant difference in the odds of adherence between tol-ER and oxy-ER. When data were pooled by formulation type, odds of adherence with IR drugs were half that for ER drugs ( $\mathrm{OR}=0.504 ; 95 \% \mathrm{CI}, 0.306-0.704$; $P<0.001$ ). Age was the only other significant predictor in the model; odds of adherence (MPR $\geq 0.80 \%$ ) for patients aged $\geq 65$ years were 1.5 times the odds for patients aged $<65$ years. The adjusted adherence rates estimated from the logistic regression model are presented in Table 5.

\section{Discussion}

The present study assessed the persistence and adherence patterns of patients using 2 dose forms of $2 \mathrm{OAB}$ medications who were enrolled in a regional managed care plan. The results demonstrated that almost half of all patients treated with an $O A B$ study drug (44.5\%) did not refill their initial prescription, and less than 1 in 7 patients (13.2\%) continued their treatment for at least 1 year. Although the type of initial therapy did not significantly affect persistence in multivariate analysis, switch rates were lower for tol-ER compared with either formulation of oxybutynin, and the ER formulations were associated with higher adherence (MPR) than the IR formulations.

Like this study, many previous studies assessing persistence and adherence to $\mathrm{OAB}$ pharmacotherapy in clinical practice ${ }^{10-12,15-18}$ were also conducted using prescription claims databases. Overall persistence in our study at 1 year (13.2\%) was within the range reported in the literature ( $8 \%$ to $29 \%$ ). ${ }^{12,13,16-18}$ Additionally, our study estimate of patients who did not refill the index prescription (44.5\%) is within the range reported in other studies (36.9\% to $48.2 \%) .{ }^{15-17}$ 


\section{Persistence, Adherence, and Switch Rates Among Extended-Release and Immediate-Release}

Overactive Bladder Medications in a Regional Managed Care Plan

\section{TABLE 5 Adjusted Study Outcomes by OAB Therapy}

\begin{tabular}{|c|c|c|c|c|c|c|}
\hline & $\begin{array}{c}\text { tol-ER } \\
(\mathrm{N}=454)\end{array}$ & $\begin{array}{c}\text { oxy-ER } \\
(\mathrm{N}=249)\end{array}$ & $\begin{array}{c}\text { tol-IR } \\
(\mathrm{N}=306)\end{array}$ & $\begin{array}{c}\text { oxy-IR } \\
(\mathrm{N}=108)\end{array}$ & $P$ Value ${ }^{a}$ & R-square b \\
\hline Persistence on index $\mathrm{Rx}$ & $11.0 \%$ & $13.2 \%$ & $9.0 \%$ & $9.0 \%$ & 0.363 & - \\
\hline Switch rate & $8.9 \%$ & $15.5 \%$ & $11.2 \%$ & $18.8 \%$ & 0.020 & $8.8 \%$ \\
\hline $\begin{array}{l}\text { Adherence } \\
M P R \geq 0.8\end{array}$ & $34.0 \%$ & $36.0 \%$ & $21.4 \%$ & $15.3 \%$ & 0.010 & $5.7 \%$ \\
\hline \multicolumn{7}{|c|}{$\begin{array}{l}\text { a } P \text { value represents the change in the significance level of the model after adding the variables representing the index overactive bladder drug to the model with all } \\
\text { covariates. Statistical significance level }(\alpha)=0.05 \text {. Significant values are shown in bold print. } \\
{ }^{b} R \text {-square represents the proportion of variation in the dependent variable explained by the model covariates. For the logistic regression models (switch rate and } \\
\text { adherence), the Nagelkerke R-square value was used. No R-square value could be computed for the Cox proportional hazards model of persistence. } \\
\text { OAB=overactive bladder; oxy-ER = oxybutynin extended-release; oxy-IR=oxybutynin immediate-release; Rx=prescription; tol-ER=tolterodine extended-release; } \\
\text { tol-IR=tolterodine immediate-release. }\end{array}$} \\
\hline
\end{tabular}

Our study population did not necessarily have a medical claim with a diagnosis of OAB. Only $53.7 \%$ of the sample was diagnosed with at least 1 symptom (ICD-9-CM code) characteristic of $\mathrm{OAB}$. This may reflect a situation of under-reporting rather than under-diagnosis, (i.e., cases of $\mathrm{OAB}$ are identified and treated by health professionals but not recorded as claims in the database). The relatively low proportion of patients with a recorded $O A B$ diagnosis is unlikely to arise from coding limitations, since the ICD-9-CM diagnosis codes used for the study were comprehensive (Table 1) 23,24 and incorporated the symptomatology of the recent definition of $\mathrm{OAB}$ by the International Continence Society. ${ }^{1}$

However, the validity of evaluating all treated patients (with or without $\mathrm{OAB}$ diagnosis) is supported by the broadly comparable demographics of the 2 subsets. The higher baseline prevalence of UTI/vulvovaginitis in patients diagnosed with $\mathrm{OAB}$ may reflect misdiagnosis in some patients, because symptoms of UTI/ vulvovaginitis can resemble those of $\mathrm{OAB} .{ }^{33}$ In addition, there were no differences in outcomes between patients with and without a diagnosis of $\mathrm{OAB}$, except that those with a diagnosis had a higher rate of switching, which might be due to increased monitoring during follow-up of diagnosed individuals.

Persistence at 6 months in our study population (20\%) was within the ranges reported in other studies ( $11 \%$ to $30 \%) .10,11,16,18$ In our study, $44.5 \%$ of patients did not refill their index prescription, suggesting that they discontinued within the first 30 days of treatment. The median days to discontinuation (non-persistency) were 31.0 overall, 33.0 for tol-ER, 34.0 for oxy-ER, 32.0 for tol-IR, and 0 for oxy-IR. It is, therefore, likely that a large proportion of patients in the present study did not achieve maximum therapeutic benefit, which may require at least 4 weeks (for oxy-ER) or 8 weeks (for tol-ER) after starting therapy or dose adjustment. ${ }^{3}$ Because low persistence may be due to inadequate or nonexistent medication counseling by prescribers, studies demonstrating the effectiveness of medication counseling on persistence rates for $\mathrm{OAB}$ medications may be needed. ${ }^{33}$ Unfortunately, there is currently limited evidence of the consequences of medication non-adherence to support such counseling in the OAB therapeutic area.

In our study, persistence on $\mathrm{OAB}$ drugs was low for all 4 study drugs, but was lowest for oxy-IR. In line with this finding, previous studies have shown lower persistence (higher discontinuation rates) with oxy-IR compared with tol-IR. ${ }^{11,14-16}$ This may reflect differences in tolerability between drugs; pooled clinical trial data have demonstrated significantly greater incidence of adverse events and a higher discontinuation rate due to adverse events with oxy-IR than with tol-IR. ${ }^{34}$ Similarly, studies comparing tol-ER and oxy-ER have demonstrated both tolerability and persistence advantages for tol-ER over oxy-ER. ${ }^{17,18,34,35}$

ER drugs had significantly greater adherence (MPR) than IR drugs, corroborating clinical trial data comparing ER and IR formulations for both oxybutynin and tolterodine. ${ }^{36,37}$ Switching was influenced by both drug type and the type of prescriber; for patients prescribed their index drug from a urologist or gynecologist, the odds of switching were 43\% lower than for patients prescribed their index drug from a physician with other specialty. However, the overall rate of switching in the present study was low (13.3\% as a proportion of all study patients, $24.0 \%$ of patients who refilled their index prescription). Because non-persistence is the result of the combined effect of switching and treatment discontinuation, reducing discontinuations must be the most important component in maintaining persistence with therapy.

In our study, age was the only patient characteristic that affected adherence; the odds of adherence were $50 \%$ higher for patients aged $\geq 65$ years than for those aged $<65$ years. In a metaanalysis, age was not consistently associated with adherence among adults with study methodology exerting greater influence than demographics. ${ }^{38}$ However, the meta-analysis evaluated adherence across 17 broad-ranging disease areas and may not reflect the situation in OAB. Based on clinical trials of OAB drugs in the elderly, some experts suggest that older patients are more 


\section{Persistence, Adherence, and Switch Rates Among Extended-Release and Immediate-Release Overactive Bladder Medications in a Regional Managed Care Plan}

likely than younger patients to respond to these medications. ${ }^{39}$ This may translate to better perception of control and subsequent higher adherence as reported in the present study.

Drug regimen factors, such as dosing frequency, can also affect adherence. ${ }^{40}$ In our study, adherence on ER formulations was twice that on IR formulations, possibly due to the convenience of once-daily dosing afforded by the ER formulations.

Of particular interest, the level of copayment did not impact persistence or adherence. This is in contrast to results from a study in which $\mathrm{OAB}$ patients not currently using medication completed a questionnaire simultaneously rating 5 attributes of treatment. ${ }^{19}$ Using conjoint analysis techniques, all 5 parameters were significant considerations (all $P<0.001$ ), with prescription drug coverage of greatest importance to patients followed by sleep disturbances, symptom concern, social interaction problems, and coping. Thus, given that paying the full medication cost was a determining factor in the decision to seek pharmacotherapy, it is interesting to note that our study did not demonstrate any impact of OOP cost on drug persistence or adherence rates. The lack of influence of OOP cost suggests that other factors, including factors not measured in our study, are more important predictors of persistence than overcoming financial barriers to treatment initiation.

\section{Limitations}

Foremost among the limitations was the low percentage of variance explained by our multivariate equations $(<10 \%)$, which suggests that unmeasured and possibly confounding factors affected persistence and adherence rates in our study sample. For example, no patient-reported data were available to document use and effectiveness of behavioral interventions that may impact medication persistence and adherence. Second, while logistic regression analysis indicated that oxy-ER or oxy-IR users remained twice as likely to switch compared with tol-ER users, and tol-IR users did not differ significantly from tol-ER users, it is possible that our year of initiation variable masked the drug effect because there were no tol-ER users until September 2001.

Third, the reasons for discontinuation are not reported, and therefore clinically justified discontinuations associated with adverse events or other reasons cannot be distinguished from discontinuations due to poor adherence associated with lack of perceived clinical benefit or need for therapy due to severity of symptoms.

Fourth, we have no information about mail order use in this population. An unknown portion of the patients who failed to refill their index prescription could have taken the medication for up to 90 days.

Fifth, the MPR value may be underestimated if medications are obtained through other means, such as samples, which are not captured by the database. On the other hand, the assumption of 'a prescription filled is a prescription taken' may not be completely true, thereby overestimating adherence. Sixth, while the level of copayment was not associated with persistence in the present study, the results are generalizable only to patients with prescription drug coverage.

\section{Conclusion}

This study demonstrated low persistence (13\%) with the $4 \mathrm{OAB}$ drugs. ER formulations of oxybutynin and tolterodine had a statistically significant adherence advantage over IR formulations. However, adherence is still low; approximately 35\% to 36\% for the ER formulation compared with $15 \%$ to $24 \%$ with the IR formulations. Patient-reported data on perceptions and experiences with drug therapy for $\mathrm{OAB}$ are needed to determine the reasons for discontinuation of drug therapy and non-adherence, particularly whether discontinuation is due to perceived lack of effectiveness or adverse effects.

\section{Authors}

ANNA O. D'SOUZA, PhD, is an analyst at Xcenda, LLC, in Palm Harbor, Florida. MICHAEL J. SMITH, PhD, RPh, is assistant professor at West Virginia University, Morgantown, West Virginia. LESLEYANN MILLER, MS, PhD, is a pharmacoeconomics research specialist in drug use policy and pharmacoeconomics at the University of Texas, MD Anderson Cancer Center, Houston, Texas. JOSEPH DOYLE, RPh, $M B A$, is director, and RINAT ARIELY, MS, MBA, is manager, Health Economics \& Outcomes Research, Global Health Economics and Outcomes Research, Novartis Pharmaceuticals Corporation, East Hanover, New Jersey.

AUTHOR CORRESPONDENCE: Anna O. D'Souza, PhD, Analyst, Xcenda, LLC, 8310 Tidewater Ct., Cincinnati, OH 45255. Tel.: 513.474.1528; Fax: 513.419.6430; E-mail: anna.dsouza @xcenda.com

\section{DISCLOSURES}

This study was performed for The HealthPlan of the Upper Ohio Valley Inc and sponsored by Novartis Pharmaceuticals. Two of the authors, Joseph Doyle and Rinat Ariely, are employees of Novartis Pharmaceuticals. The results of this study were presented at the American Society of Healthsystem Pharmacists Midyear Clinical Meeting in December 2006 (poster abstract \#41). Anna D'Souza was a PhD candidate, and Lesley-Ann Miller was an assistant professor at West Virginia University in the Department of Pharmaceutical Systems and Policy at the time of conduct of the research and writing of the manuscript.

Work on the study concept and design was shared equally by D'Souza, Smith, Miller, and Doyle. Data collection was shared equally by D'Souza, Smith, and Miller. Data interpretation was primarily the work of D'Souza with contributions by Smith, Miller, and Doyle. All authors participated in writing and revising the manuscript with D'Souza contributing the largest share. 


\section{Persistence, Adherence, and Switch Rates Among Extended-Release and Immediate-Release Overactive Bladder Medications in a Regional Managed Care Plan}

\section{ACKNOWLEDGEMENTS}

The authors acknowledge Steven Neal, Valerie Ogilbee, and Larry Wells from The HealthPlan for providing the data; and Kristijan Kahler and Annamarie Cerulli from Novartis Pharmaceuticals Corporation for their critical review of the study design and results

\section{REFERENCES}

1. Abrams P, Cardozo L, Fall M, Griffiths D, Rosier P, Ulmsten U, et al. The standardization of terminology in lower urinary tract function: report from the standardization sub-committee of the International Continence Society. Urology. 2003;61(1):37-49.

2. Yim PS, Peterson AS. Urinary incontinence. Basic types and their management in older patients. Postgrad Med. 1996;99(5):137-40, 143-44, 149-50.

3. Rovner ES, Wyman J, Lackner T, Guay D. Urinary Incontinence. In: DiPiro J, Talbert RL, Yee GC, Matzke GR, Wells BG, Posey ML, ed. Pharmacotherapy - a pathophysiologic approach. New York: Mc-Graw Hill; 2005; 1547-63.

4. Stewart K, McGhan WF, Offerdahl T, Corey R. Overactive bladder patients and role of the pharmacist. J Am Pharm Assoc. 2002;42(3):469-76.

5. Abrams P, Cardozo L, Khoury S, Wein A. Pharmacological Treatment of Urinary Incontinence. In: Abrams P, Cardozo L, Khoury S, Wein A, ed. Incontinence. Plymouth, UK: Plymbridge Distributors; 2002:479-513.

6. Chess-Williams R, Chapple CR, Yamanishi T, Yasuda K, Sellers DJ. The minor population of M3-receptors mediate contraction of human detrusor muscle in vitro. J Auton Pharmacol. 2001;21:243-48.

7. Andersson KE. Potential benefits of muscarinic $\mathrm{m} 3$ receptor selectivity. Eur Urol. 2002;1:23-28.

8. Abrams P, Andersson KE, Buccafusco JJ, Chapple C, DeGroat WC, Fryer $\mathrm{AD}$, et al. Muscarinic receptors: their distribution and function in body systems, and the implications for treating overactive bladder. Br J Pharmacol. 2006;148(5):565-78

9. Kay GG, Abou-Donia MB, Messer Jr. WS, Murphy DG, Tsao JW, Ouslander JG. Antimuscarinic drugs for overactive bladder and their potential effects on cognitive function in older patients. J Amer Geriatr Soc 2005;53:2195-201

10. Desgagne A, Lelorier J. Incontinence drug utilization patterns in Quebec, Canada. Value Health. 1999;2(6):452-58.

11. Lawrence M, Guay DR, Benson SR, Anderson MJ. Immediate-release oxybutynin versus tolterodine in detrusor overactivity: a population analysis. Pharmacotherapy. 2000;20(4):470-75.

12. Malone DC, Okano GJ. Treatment of urge incontinence in Veterans Affairs medical centers. Clin Ther. 1999;21(5):867-77.

13. Baigrie RJ, Kelleher JP, Fawcett DP, Pengelly AW. Oxybutynin: is it safe? Br J Urol. 1988;62(4):319-22.

14. Zhou Z, Barr C, Torigoe Y, Williamson T. Persistence of therapy with drugs for overactive bladder. [poster abstract] Value Health. 2001;4(2):162-63.

15. Juzba M, White TJ, Chang EY. Prevalence and cost analysis of overactive bladder in a managed care organization. [poster abstract] J Manag Care Pharm. 2001;7(5):365. Available at: www.amcp.org/data/jmcp/ Abstracts-355-373.pdf.

16. Yu YF, Nichol MB, Yu AP, Ahn J. Persistence and adherence of medications for chronic overactive bladder/urinary incontinence in the California Medicaid program. Value Health. 2005;8(4):495-505.

17. Shaya FT, Blume S, Gu A, Zyczynski T, Jumadilova Z. Persistence with overactive bladder pharmacotherapy in a Medicaid population. Am J Manag Care. 2005;11(4 Suppl):S121-S29.
18. Varadharajan S, Jumadilova Z, Girase P, Ollendorf DA. Economic impact of extended-release tolterodine versus immediate- and extended-release oxybutynin among commercially insured persons with overactive bladder. Am J Manag Care. 2005;11(4 Suppl):S140-S49.

19. Harpe SE, Szeinbach SL, Caswell RJ, Corey R, McAuley JW. The relative importance of health related quality of life and prescription insurance coverage in the decision to pharmacologically manage symptoms of overactive bladder. J Urol. 2007;178(6):2532-36.

20. Sikka R, Xia F, Aubert RE. Estimating medication persistency using administrative claims data. Am J Manag Care. 2005;11(7):449-57.

21. Steiner JF, Prochazka AV. The assessment of refill compliance using pharmacy records: methods, validity, and applications. J Clin Epidemiol. 1997;50(1):105-16.

22. Fairman K, Motheral B. Evaluating medication adherence: Which measure is right for your program? J Manag Care Pharm. 2000;696:499-504. Available at: www.amcp.org/data/jmcp/ce_v6_499-506.pdf.

23. Nitz NM, Jumadilova Z, Darkow T, Frytak JR, Bavendam T. Medical costs after initiation of drug treatment for overactive bladder: effects of selection bias on cost estimates. Am J Manag Care. 2005;11(4 Suppl):S130-S39.

24. Day PL. Findings of a three-year retrospective study to investigate prevalence and incidence of urinary incontinence and overactive bladder in a typical managed care setting. Pharm Pract Manag Q. 2000;20(1):1-11.

25. Brown JS, McGhan WF, Chokroverty S. Comorbidities associated with overactive bladder. Am J Manag Care. 2000;6(11 Suppl):S574-S79.

26. Wagner TH, Hu TW, Bentkover J, LeBlanc K, Stewart W, Corey R, et al Health-related consequences of overactive bladder. Am J Manag Care. 2002; 8(19 Suppl):S598-S607

27. Detrol ${ }^{\circledR}$ LA (tolterodine tartrate extended release tablets). Prescribing Information. Pharmacia \& Upjohn, New York, NY, USA. October 2005.

28. Detrol ${ }^{\circledR}$ (tolterodine tartrate tablets). Prescribing Information. Pharmacia \& Upjohn, New York, NY, USA. October 2005.

29. Ditropan XL ${ }^{\circledR}$ (oxybutynin chloride extended release tablets). Prescribing Information. Ortho-McNeil Pharmaceutical Inc., Raritan, NJ, USA. June 2004

30. Ditropan ${ }^{\circledR}$ (oxybutynin chloride tablet and syrup). Prescribing Information. Ortho-McNeil Pharmaceutical, Inc., Raritan, NJ, USA. September 2003.

31. Claxton AJ, Li Z, McKendrick J. Selective serotonin reuptake inhibitor treatment in the UK: risk of relapse or recurrence of depression. $\mathrm{Br} \mathrm{J}$ Psychiatry. 2000 August;177:163-68.

32. Persistence, adherence, and risk of discontinuation associated with commonly prescribed antihypertensive drug monotherapies. J Am Board Fam Med. 2007;20:72-80.

33. Noe L, Sneeringer R, Patel B, Williamson T. The implications of poor medication persistence with treatment for overactive bladder. Manag Care Interface. 2004;17(11):54-60.

34. Appell RA. Clinical efficacy and safety of tolterodine in the treatment of overactive bladder: a pooled analysis. Urology. 1997;50(6A Suppl):90-96.

35. Diokno AC, Appell RA, Sand PK, Dmochowski RR, Gburek BM, Klimberg IW, et al. Prospective, randomized, double-blind study of the efficacy and tolerability of the extended-release formulations of oxybutynin and tolterodine for overactive bladder: results of the OPERA trial. Mayo Clin Proc. 2003;78(6):687-95.

36. Anderson RU, Mobley D, Blank B, Saltzstein D, Susset J, Brown JS. Once daily controlled versus immediate release oxybutynin chloride for urge urinary incontinence. OROS Oxybutynin Study Group. J Urol. 1999;161(6):1809-12

37. Van Kerrebroeck P, Kreder K, Jonas U, Zinner N, Wein A. Tolterodine once-daily: superior efficacy and tolerability in the treatment of the overactive bladder. Urology. 2001;57(3):414-21. 
Persistence, Adherence, and Switch Rates Among Extended-Release and Immediate-Release Overactive Bladder Medications in a Regional Managed Care Plan

38. DiMatteo MR. Variations in patients' adherence to medical recommendations: a quantitative review of 50 years of research. Med Care. 2004; 42(3):200-09.

39. Ouslander JG, Shih YT, Malone-Lee J, Luber K. Overactive bladder: special considerations in the geriatric population. Am J Manag Care. 2000; 6(11 Suppl):S599-S606.
40. Paes AH, Bakker A, Soe-Agnie CJ. Impact of dosage frequency on patient compliance. Diabetes Care. 1997;20(10):1512-17. 